\title{
Why people select the outpatient clinic of medical centers: A nationwide analysis in Taiwan
}

\author{
Ming-Hwai Lin ${ }^{\text {Corresp., } 1,2}$, Hsiao-Ting Chang ${ }^{1,2}$, Tzeng-Ji Chen ${ }^{1,2}$, Shinn-Jang Hwang ${ }^{1,2}$ \\ 1 Department of Family Medicine, Taipei Veterans General Hospital, Taipei, Taiwan \\ 2 School of Medicine, National Yang-Ming University, Taipei, Taiwan \\ Corresponding Author: Ming-Hwai Lin \\ Email address: mhlin@vghtpe.gov.tw
}

Introduction. In contrast to other countries, Taiwan's National Health Insurance (NHI) program allows patients to freely select the specialists and tiers of medical care facility without a referral. Some medical centers in Taiwan receive over 10,000 outpatients per day. In the NHI program, the co-payment was increased for high-tier facilities for outpatient visits in 2002, 2005, and 2017. However, the policies only mildly reduced the use of high-tier medical care facilities. The main purpose of this study was to evaluate the factors contributing to the patients' selection of the outpatient clinic of medical centers without a referral.

Methods. An online anonymous survey was conducted by using Google Form platform utilizing selfconstructed questionnaire from September to October 2018. A nationwide sample in Taiwan was recruited using convenience sampling through social media. Based on a literature review and a focus group, 20 factors that may affect the choice of the outpatient institution were constructed. The associations between items that affect the patients selection of outpatient clinics were assessed using exploratory factor analysis. Principal axis factoring was performed to identify the major factors affecting the decision. Multiple logistic regression was performed to determine which factors satisfactorily explained "visiting the outpatient clinic of the medical center for an illness without a referral."

Results. During the survey period, 5060 people browsed the online survey, and 1003 responded and completed the online questionnaire. Therefore, the response rate was $19.8 \%$. A total of 987 valid responses was collected. Exploratory factor analysis revealed that three main factors, namely the "physician factor," "image and reputation factor," and " facility and medication factor," affected the selection of outpatient clinics. A series of logistic regressions indicated that patients who reported that hospital facilities, high-quality drugs, and diverse specialties were very important were more likely to select the outpatient clinic of a medical center $(\mathrm{OR}=2.218,95 \% \mathrm{Cl}=1.514-3.249)$. Patients who reported that physician factors were very important were less likely to select a medical center $(O R=$ $0.717,95 \% \mathrm{Cl}=0.523-0.984)$. Patients who were previously satisfied with their experience of the primary clinics or had a regular family doctor were less likely to choose a medical center $(O R=0.509$, $95 \% \mathrm{Cl}=0.435-0.595$ and $\mathrm{OR}=0.676,95 \% \mathrm{Cl}=0.471-0.969)$.

Conclusion. In Taiwan, patients with good primary medical experience and regular family physicians had significantly lower rates by selecting the outpatient clinic of a medical center. The results of this study support that the key to establishing graded medical care is to prioritize the strengthening of the primary medical system. 
1 Article

2 Why people select the outpatient clinic of medical centers: A

3 nationwide analysis in Taiwan.

4

5 Ming-Hwai Lin ${ }^{1,2, *}$, Tzeng-Ji Chen ${ }^{1,2}$, and Shinn-Jang Hwang 1,2

61 Department of Family Medicine, Taipei Veterans General Hospital, No. 201, Sec. 2, Shi-Pai

7 Road, Taipei 112, Taiwan

82 School of Medicine, National Yang-Ming University, No.155, Sec.2, Linong Street, Taipei,

9 112, Taiwan

10 * Author to whom correspondence should be addressed; E-Mail: minghwai@gmail.com; Tel.: +886-2-2875-7458; Fax: +886-2-2873-7901.

12

13

14

15

16

17

18

19

20

21

22

23

24

25

26

Academic Editor:

Received: / Accepted: /Published:

\section{Abstract:}

Introduction. In contrast to other countries, Taiwan's National Health Insurance (NHI) program allows patients to freely select the specialists and tiers of medical care facility without a referral. Some medical centers in Taiwan receive over 10,000 outpatients per day. In the NHI program, the co-payment was increased for high-tier facilities for outpatient visits in 2002, 2005, and 2017. However, the policies only mildly reduced the use of high-tier medical care facilities. The main purpose of this study was to evaluate the factors contributing to the patients' selection of the outpatient clinic of medical centers without a referral.

Methods. An online anonymous survey was conducted by using Google Form platform utilizing self-constructed questionnaire from September to October 2018. A nationwide sample in Taiwan was recruited using convenience sampling through social media. Based on a literature review and a focus group, 20 factors that may 
27

28

29

30

31

32

33

34

35

36

37

38

39

40

41

42

43

44

45

46

47

48

49

50

51

52

53

54

55

56

57

58

59

affect the choice of the outpatient institution were constructed. The associations between items that affect the patients selection of outpatient clinics were assessed using exploratory factor analysis. Principal axis factoring was performed to identify the major factors affecting the decision. Multiple logistic regression was performed to determine which factors satisfactorily explained "visiting the outpatient clinic of the medical center for an illness without a referral."

Results. During the survey period, 5060 people browsed the online survey, and 1003 responded and completed the online questionnaire. Therefore, the response rate was $19.8 \%$. A total of 987 valid responses was collected. Exploratory factor analysis revealed that three main factors, namely the "physician factor," "image and reputation factor," and " facility and medication factor," affected the selection of outpatient clinics. A series of logistic regressions indicated that patients who reported that hospital facilities, high-quality drugs, and diverse specialties were very important were more likely to select the outpatient clinic of a medical center $(\mathrm{OR}=2.218,95 \% \mathrm{CI}=1.514-3.249)$. Patients who reported that physician factors were very important were less likely to select a medical center $(\mathrm{OR}=$ $0.717,95 \% \mathrm{CI}=0.523-0.984)$. Patients who were previously satisfied with their experience of the primary clinics or had a regular family doctor were less likely to choose a medical center $(\mathrm{OR}=0.509,95 \% \mathrm{CI}=0.435-0.595$ and $\mathrm{OR}=0.676,95 \% \mathrm{CI}=0.471-0.969)$.

Conclusion. In Taiwan, patients with good primary medical experience and regular family physicians had significantly lower rates by selecting the outpatient clinic of a medical center. The results of this study support that the key to establishing graded medical care is to prioritize the strengthening of the primary medical system.

Keywords: health care seeking behavior; national health programs; hospital outpatient clinic; healthcare survey; single-payer system

\section{Introduction}

The National Health Insurance (NHI) program in Taiwan is a single-payer system founded in 1995. The NHI program comprises a hierarchy of medical care facilities consisting of four tiers: medical centers, regional hospitals, local community hospitals, and primary clinics. However, referral systems have not yet been successfully implemented. 
60

61

62

63

64

65

66

67

68

69

70

71

72

73

74

75

76

77

78

79

80

81

82

83

84

85

86

87

88

89

90

Hierarchical medical care means that medical resources can be used the most efficiently through professional division in the medical system. In most countries, primary care physicians act as healthcare "gatekeepers" by providing initial medical interventions and referring patients to additional specialists (Yan, Kung \& Lu, 2019). Excluding situations of major illnesses and the urgent requirement of treatment at a medical center, people should first consult a family doctor or a nearby primary clinic regarding an illness. After diagnosis and treatment, patients can be referred to other specialty clinics or hospitals.

In contrast with other countries, patients in Taiwan have full and unrestricted access to all medical care facilities. Patients in Taiwan's NHI program can freely select specialists and the tier of medical care facility directly without a referral (Lynn et al., 2015). The design of global budget payments and the fee for services result in patients favoring treatment at large hospitals, even for mild diseases, and medical centers are more likely to use advanced instruments and pharmaceuticals (Kuo, Chen \& Lin, 2019; Lee et al., 2018). Numerous patients in Taiwan consult several physicians with different specialties and at different health care facilities and switch physicians and facilities rapidly (Wang \& Lin, 2010). This phenomenon has been suggested as a source of inefficiency in healthcare use and has resulted in high medical expenditures and costs of outpatient visits.

Studies have reported that people in developed countries visit a doctor 5-6 times a year, whereas in Taiwan, the average frequency of visits is 13 . More than 30,000 insured residents in Taiwan seek hospital inpatient and outpatient services over 100 times a year (Lynn et al., 2015). In certain large medical centers in northern Taiwan, the number of outpatients per day often exceeds 10,000 . Furthermore, physicians frequently see over 50 patients in a morning, spending only 5 minutes or less for each consultation (Wu, Majeed \& Kuo, 2010). These short consultations can cause misinformation and misunderstanding between healthcare providers and patients because of the time to build rapport. The freedom to have multiple hospital return visits results in high use of outpatient hospital visits, drug prescriptions, and other health services (Wang \& Lin, 2010; Yip et al., 2019).

87 Excessive use of health services is a critical and persistent problem in Taiwan. To moderate these rising costs, a graded medical system was implemented in the NHI program and increased the copayment for high-tier facilities for outpatient visits in 2002, 2005, and 2017. Patients without a referral are charged an additional copayment ranging from 240 to 420 NTD 
91 (approximately 8 to 14 USD) for every visit to a high-tier medical facility. Although changes to 92 the NHI copayment policies have mildly reduced the use of high-tier medical care facilities, 93 studies have indicated that the effect of medical prices on people's medical behavior is very 94 limited (Lee et al., 2018). The implementation of the copayment system exerted little effect on 95 encouraging the population visit primary clinics first (Yang, Tsai \& Tien, 2019).

96 Factors affecting patients' selection of high-tier medical care facilities have not been fully 97 identified. Cheng et al. reported that patients tend to base their judgment of hospital quality on 98 medical equipment (Cheng, 2015 . The main purpose of this study was to evaluate the factors 99 contributing to the patients' selection of the outpatient clinic of medical centers without a 100 referral. Understanding motivations underlying the public's choices would enable the 101 implementation of a successful graded medical system in Taiwan.

102

\section{2. Materials and Methods}

104

105

106

107

108

109

110

111

112

113

114

115

116

117

118

119

120

121

\subsection{Study design}

The present study was a web-based cross-sectional online survey. The development and reporting of the survey were performed following the guidelines of the Checklist for Reporting Results of Internet E-survey (CHERRIES) (Eysenbach, 2004). The checklist is available in supplementary data. The questionnaire was developed in Google forms (https://www.google.com/forms/about/).

After the initial tests and revision of the questionnaire were completed, and a nationwide sample in Taiwan was recruited using convenience sampling through an online anonymous survey from September 3 to October 31, 2018. The questionnaire was administered to various community groups by using the snowball sampling method. To maximize public outreach, the survey was promoted on various social media platforms, such as Facebook, Line, and the most popular bulletin board system (https://facebook.com/; https://linecorp.com/; and https://www.ptt.cc/index.bbs.html). Interested citizens were invited to complete the questionnaire and respondents were asked to invite their friends to participate in the survey and fill out the questionnaire.

The link to the survey was available for 8 weeks. All participants were invited to complete an anonymous self-administered online questionnaire, which required approximately 10 minutes to complete. Informed consent was requested from all participants on the first page of the 
122 questionnaire. Only participants who were at least 20 years old and were able to read Chinese

123 fluently were given access. No rewards were provided to participants. A deduplication protocol

124 was applied to identify multiple submissions and preserve data integrity, including cross-

125 validation of the eligibility criteria of key variables and discrepancies in key data (Bowen et al., 126 2008).

127 This study was approved by the Institutional Review Board of Taipei Veterans General 128 Hospital (2017-07-009AC), and the study was conducted following the guidelines of the 129 Helsinki declaration of 2013.

130

131

132

133

134

135

136

137

138

139

140

141

142

143

144

145

146

147

148

149

150

151

152

\subsection{Questionnaire design}

A questionnaire was developed because no similar questionnaires related to the selection of outpatient clinics are available. The questionnaire was finalized after experts were invited to review and revise. A literature search was performed for publications that discussed the factors affecting the selection of outpatient clinics. Search terms used were " health care seeking behavior," " hospital outpatient clinics," and a combination of the two. Based on factors identified in the literature search, two family physicians, three outpatient nurses, and five volunteers were invited to participate in the focus group. The main topic was "What are the important factors in the selection of an outpatient clinic by a patient." Opinions provided by the experts were used as a reference for the questionnaire.

Based on a literature review and the opinions of the focus group, factors that related to the selection of outpatient clinic were proposed and included in the questionnaire. The main dependent variable of this study was "preferred choice of outpatient clinics when you are ill," and the independent variables were assessed using the following question: "Please indicate the importance of each of the following factors in your selection of an outpatient clinic when you were ill?" A total of 20 factors affecting the choice of the outpatient institution was included. All respondents were asked to rate the importance of the 20 factors in the selection of an outpatient institution when they were ill on a 5-point Likert scale ranging from $1=$ not at all important to 5 $=$ very important.

At the end of the questionnaire, respondents were asked to provide demographic information and information on past experiences during outpatient visits at different hospital levels, attitudes towards copayment, and whether they have a regular family physician. The 
153 questionnaire was developed based on a literature review and the opinions of the focus group to

154 ensure content validity. Five senior researchers with subject matter expertise were invited to

155 revise the questionnaire and perform repeated testing of the questionnaire. The content was rated

156 by five experts with an average content validity index of $86.0 \%$. The questions were refined after

157 feedback and finalized into an online survey.

158 At the beginning of the study, the questionnaire was pretested in 20 patients to determine if

159 the content was appropriate and to ascertain whether the content was understandable. The

160 internal consistency reliability test was used for reliability analysis. Cronbach's alpha of the

161 questionnaire was 0.895 , which is satisfactory.

162

163

\subsection{Statistical analysis}

164

All data were stored on a secure server and backed up on a local hard disk to ensure the

165

166

167

168

169

170

171

172

173

174

175

176

177

178

179

180

181

182

security of the data. Only the researcher could access these materials. The data were primarily evaluated by Dr. Lin, Ming-Hwai. The survey data were extracted into Excel (Microsoft Corp), and statistical analyses were performed using the Statistical Package for the Social Sciences (SPSS, version 20.0; SPSS Inc., Chicago, IL, USA).

Descriptive statistics were used to present the results for patient hospital choices. Independent samples t-tests and Chi-square tests were adopted to examine the association between respondents' demographic characteristics and their outpatient preference. The normality of the collected data was analyzed using the Kolmogorov-Smirnov test. The data followed a normal distribution; thus, comparisons among the three groups were performed using analysis of variance (ANOVA).A p value of $<0.05$ (two-tailed) was considered statistically significant.
The associations between items that affect the patients' choice of outpatient clinics were assessed using exploratory factor analysis. Measures of sample adequacy, such as Kaiser-MeyerOlkin (0.868) and Bartlett's Test of Sphericity (significance $<0.001$ ), indicated that factor analysis could be applied. Principal axis factoring was performed to identify the major factors by using a correlation matrix and oblimin rotation. The number of principal components to be extracted was determined by examining the eigenvalues $(>1)$. Loadings of over 0.5 were used to interpret components in the study. The number of domains was reduced to three and named "physician factor, " "image and reputation factor," and "facility and medication factor.". Internal 
183 consistency was demonstrated, with the factors' Cronbach's $\alpha$ coefficients ranging from 0.792 to 1840.905 . These three factors accounted for $61.7 \%$ of the total variance of the variables.

185 Multiple logistic regressions were performed to determine factors that satisfactorily 186 explained the dependent variable "visiting the outpatient clinic of the medical center for an

187 illness without a referral." The adjusted odds ratios (ORs) with 95\% confidence intervals (CIs)

188 for predicting "visit to the outpatient clinic of a medical center for an illness" were computed. In 189 model 1, the association of age, gender and personal experience of primary clinics was tested.

190 The physician factor, image and reputation, and facility and medication factors were included in

191 model 2 to test the associations beyond the personal factors. The other variables were included in 192 model 3 to test the association of sociodemographic factors, in addition to the aforementioned 193 factors.

194

195 3. Results

196 During the survey period, 5060 people browsed the online survey, and 1003 responded and 197 completed the online questionnaires. Therefore, the response rate was $19.8 \%$. We excluded 16 198 participants because of duplication (the same age, occupation, and answer options). Table 1 199 provides a comparison of the demographic characteristics of the patients who favor different 200 institutions for outpatient visits.

201 The mean age of the respondents was 43.6 years (SD, minimum, and maximum were 10.6, 20219 , and 85 years, respectively). Men accounted for $43.8 \%$ and women accounted for $56.2 \%$ of 203 the 987 respondents included; 509 (51.6\%) respondents favored visiting a primary clinic, 308 $204(31.2 \%)$ favored visiting the general hospital, and $170(17.2 \%)$ favored visiting the medical 205 center without a referral. Table 1 provides a comparison of demographic characteristics and 206 preferred institutions for outpatient visits. Gender, marital status, and education level were not 207 statistically related to the choice of outpatient visits. In univariate analysis, the choice of medical 208 treatment facility was statistically related to income $(\mathrm{p}=0.026)$. Patients with a monthly income 209 of NTD 50,001-70,000 favored outpatient clinics of medical centers. People living in urban 210 areas accounted for $65.8 \%$ of respondents. A larger number of people living in urban areas

211 favored medical centers than patients living in other areas $(\mathrm{p}<0.001)$. Approximately $51.5 \%$ of

212 the respondents had regular family doctors. Significantly more patients who favor primary

213 clinics for outpatient visits had regular family doctors than patients who prefer medical centers 
$214(61.9 \%$ vs $41.2 \%, \mathrm{p}<0.001)$. Approximately $67.6 \%$ of the respondents were satisfied with their 215 previous medical experience in primary care. Furthermore, patients who favored primary clinics 216 for outpatient visits exhibited significantly higher satisfaction rates than patients who favored 217 medical centers $(75.2 \%$ vs $52.9 \%, \mathrm{p}<0.001)$.

218 Table 2 summarizes the average rating of respondents on the importance of each factor 219 when selecting an outpatient facility and their preferred outpatient institution. "Physicians were 220 highly reputable," "physicians explained in detail," and "physicians have a good medical 221 practice" were the rated most important factors to consider when selecting the outpatient 222 institution. The low copayment was the least important factor for outpatient medical choice 223 among all patients (Likert scale rating of $3.08 \pm 1.16$ ).

224 In univariate analysis, six factors were significantly more important among the respondents 225 who chose to visit a medical center $(\mathrm{p}<0.001)$. These factors were "physicians are highly 226 reputable," "physicians have a good medical practice," " the institution has advanced 227 equipment," "the institution has high-quality drugs," "the institution has diverse specialties, " and 228 "the institutions has a good reputation". In this study, we conducted exploratory factor analysis to 229 understand the potential common characteristics among factors and clarify the influencing 230 factors. We used principal component analysis to extract data using a correlation matrix and 231 oblimin rotation method. We removed six items because of cross-loading or because the factor 232 load was too low $(<0.4)$. Factors with eigenvalues greater than 1, cumulative percentages of 233 variance explained above $71.2 \%$, KMO value reaching of 0.868 , and $p$ value less then 0.001 234 were excluded. Three main factors were retained in the final extraction (Table 3), namely 235 "physician factor," "image and reputation factor," and "facility and medication factor." We 236 subsequently converted the scores to three factors into a multivariable analysis model.

237 Table 4 illustrates three models of logistic regression for predicting "visits to the outpatient 238 clinic of the medical center for an illness." Age was a crucial predictor in all the models. The 239 likelihood of choosing to visit a medical center when ill increased by $2.7 \%-3.1 \%$ for every 240 additional year of age $(95 \% \mathrm{CI}=1.4 \%-4.3 \%)$ when other variables were controlled.

241 In Model 1, when age, gender, "have a regular family physician," and "consider that 242 copayment is important" were adjusted, patients who were previously satisfied with the medical 243 experience of primary clinics had a 0.5 lower likelihood of visiting the outpatient clinic of a 244 medical center for an illness $(95 \% \mathrm{CI}=0.429-0.584)$. 
245

246

247

248

249

250

251

252

253

254

255

256

257

258

259

260

261

262

263

264

265

266

267

268

269

270

271

272

273

274

Model 2 was then also adjusted for the extracted factors I to III, which revealed that patients who reported that hospital facilities, high-quality drugs, and diverse specialties were very important had a 2.218 higher likelihood of selecting the outpatient clinic of the medical center $(\mathrm{OR}=2.218,95 \% \mathrm{CI}=1.514-3.249)$. Patients who were previously satisfied with the medical experience of primary clinics had a 0.509 lower likelihood of choosing a medical center to visit when ill $(95 \% \mathrm{CI}=0.435-0.595)$. Patients who rated copayment as important were 0.525 times as likely to select a medical center to visit when ill $(95 \% \mathrm{CI}=0.354-0.781)$. People with a regular family doctor were 0.676 times less likely to select a medical center $(95 \% \mathrm{CI}=0.471-$ 0.969). Patients who rated physician factors as very important were less likely to select an outpatient clinic in a medical center $(\mathrm{OR}=0.717,95 \% \mathrm{CI}=0.523-0.984)$. The gender of the patient and the image and reputation of the hospital and physicians were not significantly related to inpatient hospital choice.

In Model 3, when the possible sociodemographic confounding variables were added, the step Wald chi-square statistic was insignificant (Wald chi-square difference $=13.581, \mathrm{df}=8, \mathrm{p}=$ 0.093). The residential area, income, and education level did not appear to be related to the selection of an outpatient clinic. Therefore, we decided to adopt model 2 as the result of our analysis.

\section{Discussion}

Several factors significantly affected the selection of a medical center, including older age, the physician factors, advanced equipment, high-quality drugs, past experience in primary clinics and the copayment. Most of the Taiwanese population agree with the principle of a hierarchical medical system and a medical referral system. However, many people still disagree with changes to their health care-seeking choices because of policy promotion (Yan, Kung \& $L u$, 2019). A survey determined that age, residence, education, and monthly family income were significantly related to inpatient hospital choice (Kamra, Singh \& De, 2016). Some results were consistent with ours. However, in our study, income did not have an obvious effect on outpatient choice. This may be because of the exemption for low-income people in Taiwan's health insurance. Low-income residents do not pay any component when visiting a medical center without a referral (Yang, Tsai \& Tien, 2019). 
275 Family physicians were introduced over 20 years ago in Taiwan. However, only 51.5\% of

276 the respondents had regular family doctors. In this study, patients with regular family doctors,

277 who were satisfied with their medical experience in primary care, who rated the physician factor

278 as important, and who rated copayment as important, were less likely to select a medical center

279 when ill. These results indicated that the implementing a family physician system, whereby the

280 public generally has a trusted family doctor, would help reduce the number of patients electing to

281 go directly to the medical centers without a referral.

282

Gender, marital status, and education level did not affect the choice of outpatient visits. The

284

285

286

287

288

289

290

291

292

293

294

295

296

297

298

299

300

301

302

303

304

305

univariate analysis indicated that the choice of the outpatient institution was only slightly related

to income levels, and income levels were not related to the outpatient choice, after controlling for other variables in regression analysis. Low copayment was the least important factor for outpatient medical choice among all patients. This result may be caused by the low copayment amount in Taiwan's NHI system. Furthermore, in the NHI program, most of the cost of medical treatment is waived for low-income households and catastrophic illness patients in Taiwan. Thus, the financial burden is rarely a consideration in the patients' choice of outpatient institution (Chen \& Fan, 2015). The current copayment of outpatient medicines is a fixed fee, and the out of pocket maximum is only NTD\$200 (approximately USD\$6.7). Although the NHI copayment reforms had mildly reduced the probability that patients with minor ailments would choose to visit high-tier medical facilities, several studies have indicated that the effect of medical prices on people's medical behavior is limited.

In the present research, a similar phenomenon was also observed. Low copayment had the lowest average rating on the Likert scale when considering the importance of outpatient medical choices among all patients. Changes to the health insurance system (e.g., changing the copayment to a fixed-rate coinsurance) may be the only method to eliminate unnecessary testing and medical waste (Victor et al., 2018).

Ideally, every older adult should have trusted primary care physicians who can provide outpatient services. However, in this study, older people had a greater likelihood to visit the medical center for outpatient visits. In 2012, Liu et al. indicated that the different health profiles of elderly people significantly affected the likelihood of use and expenditure on health care services. The high comorbidity group tended to use more ambulatory care services, and the frail

Peer) reviewing PDF | (2020:04:47877:2:0:NEW 4 Aug 2020) 
306 group had higher health care expenditures (Liu, Tian \& Yao, 2012). Our research results did not

307 accord with these findings. Further research is needed to understand whether the primary clinics

308 in Taiwan satisfy the needs of elderly people.

309 This study has several limitations that may affect the findings. First, participants were

310 recruited over the Internet because of the web-based survey design, thus the low response rate

311 warrants further exploration. Although the online survey represents a wide age range and

312 geographic distribution, the sample was younger and more highly educated than the general

313 public (Tengilimoglu et al., 2017). Hsieh et al. determined that Internet use in Taiwan was

314 significantly associated with more outpatient clinic visits among people with chronic diseases in

315 Taiwan (Hsieh et al., 2016); therefore, caution should be exercised when generalizing these

316 results. Second, the variance explained by the logistic regression model suggests that other

317 significant factors may determine outpatient clinic decisions (Cheng, 2015; Yip et al., 2019).

318 Despite these limitations, this study is the first to investigate how the public chooses

319 outpatient institutions in Taiwan. Further research should explore the influencing factors among 320 the older group.

321

322 5. Conclusions

323 A good primary medical experience and a regular family physician significantly reduces

324 people's likelihood of visiting the medical center without a referral. The results of this study

325 support that the key to establishing graded medical care is prioritizing the strengthening of the 326 primary medical system.

327

328 Acknowledgments

329 This study was supported by grants from the Ministry of Science and Technology (MOST 330 106-2314-B-075 -032 -MY3) and Taipei Veterans General Hospital (V107C-095).

\section{Author Contributions}

332 Ming-Hwai Lin conceived the idea for this study, carried out the analyses, and drafted the 333 manuscript. Tzeng-Ji Chen and Shinn-Jang Hwang revised the manuscript. All the authors 334 approved the final version of the manuscript.

335 Conflicts of Interest 
336

337

338

339

340

341

342

343

344

345

346

347

348

349

350

351

352

353

354

355

356

357

358

359

360

361

362

363

364

365

The authors declare that there are no conflicts of interest.

\section{References}

Bowen AM, Daniel CM, Williams ML, and Baird GL. 2008. Identifying multiple submissions in Internet research: preserving data integrity. AIDS and Behavior 12:964-973. $10.1007 / \mathrm{s} 10461-007-9352-2$

Chen B, and Fan VY. 2015. Strategic Provider Behavior Under Global Budget Payment with Price Adjustment in Taiwan. Health Economics 24:1422-1436. 10.1002/hec.3095 Cheng TM. 2015. Reflections on the 20th anniversary of Taiwan's single-payer National Health Insurance System. Health Affairs 34:502-510. 10.1377/hlthaff.2014.1332

Eysenbach G. 2004. Improving the quality of Web surveys: the Checklist for Reporting Results of Internet E-Surveys (CHERRIES). Journal of Medical Internet Research 6:e34. 10.2196/jmir.6.3.e34

Hsieh RW, Chen L, Chen T-F, Liang J-C, Lin T-B, Chen Y-Y, and Tsai C-C. 2016. The association between internet use and ambulatory care-seeking behaviors in Taiwan: a cross-sectional study. Journal of Medical Internet Research 18:e319.

Kamra V, Singh H, and De KK. 2016. Factors affecting hospital choice decisions: An exploratory study of healthcare consumers in Northern India. Asia Pacific Journal of Health Management 11:76.

Kuo RN, Chen W, and Lin Y. 2019. Do informed consumers in Taiwan favour larger hospitals? A 10-year population-based study on differences in the selection of healthcare providers among medical professionals, their relatives and the general population. BMJ open 9:e025202-e025202. 10.1136/bmjopen-2018-025202

Lee YH, Ang TFA, Chiang TC, and Kaplan WA. 2018. Growing concerns and controversies to Taiwan's National Health Insurance-what are the lessons from mainland China, South Korea and Singapore? International Journal of Health Planning and Management 33:e357-e366. 10.1002/hpm.2387

Liu LF, Tian WH, and Yao HP. 2012. Utilization of health care services by elderly people with National Health Insurance in Taiwan: the heterogeneous health profile approach. Health Policy 108:246-255. 10.1016/j.healthpol.2012.08.022 
366 Lynn AM, Shih TC, Hung CH, Lin MH, Hwang SJ, and Chen TJ. 2015. Characteristics of

367

368

369

370

371

372

373

374

375

376

377

378

379

380

381

382

383

384

385

386

387

388 ambulatory care visits to family medicine specialists in Taiwan: a nationwide analysis. PeerJ 3:e1145. 10.7717/peerj.1145

Tengilimoglu D, Sarp N, Yar CE, Bektaş M, Hidir MN, and Korkmaz E. 2017. The consumers' social media use in choosing physicians and hospitals: the case study of the province of Izmir. The International journal of health planning and management 32:19-35.

Victor V, Joy Thoppan J, Jeyakumar Nathan R, and Farkas Maria F. 2018. Factors Influencing Consumer Behavior and Prospective Purchase Decisions in a Dynamic Pricing Environment-An Exploratory Factor Analysis Approach. Social Sciences 7:153.

Wang MJ, and Lin SP. 2010. Study on doctor shopping behavior: insight from patients with upper respiratory tract infection in Taiwan. Health Policy 94:61-67. 10.1016/j.healthpol.2009.08.009

Wu TY, Majeed A, and Kuo KN. 2010. An overview of the healthcare system in Taiwan. London J Prim Care (Abingdon) 3:115-119. 10.1080/17571472.2010.11493315

Yan Y-H, Kung C-M, and Lu C-L. 2019. A Study on the Public Awareness of Hierarchical Medical System in Taiwan. Health 11:361-370.

Yang CJ, Tsai YC, and Tien JJ. 2019. Patients with minor diseases who access high-tier medical care facilities: New evidence from classification and regression trees. International Journal of Health Planning and Management 34:e1087-e1097. 10.1002/hpm.2745

Yip WC, Lee YC, Tsai SL, and Chen B. 2019. Managing health expenditure inflation under a single-payer system: Taiwan's National Health Insurance. Social Science and Medicine 233:272-280. 10.1016/j.socscimed.2017.11.020 


\section{Table $\mathbf{1}$ (on next page)}

Table 1. Demographic characteristics and preferred institution for outpatient visits $(\mathrm{N}=$ 987) 
1 Table 1. Demographic characteristics and preferred institution for outpatient visits $(\mathrm{N}=987)$

\begin{tabular}{|c|c|c|c|c|c|}
\hline & \multirow[b]{2}{*}{ total } & \multicolumn{3}{|c|}{ preferred institution for outpatient visit } & \multirow{4}{*}{$p$ value } \\
\hline & & $\begin{array}{l}\text { primary } \\
\text { clinic }\end{array}$ & $\begin{array}{l}\text { general } \\
\text { hospital }\end{array}$ & $\begin{array}{l}\text { medical } \\
\text { center }\end{array}$ & \\
\hline & $n=987$ & $\mathrm{n}=509$ & $\mathrm{n}=308$ & $\mathrm{n}=170$ & \\
\hline & $n(\%)$ & $n(\%)$ & $n(\%)$ & $n(\%)$ & \\
\hline age (mean, SD) & $43.6(10.6)$ & $41.7(10.7)$ & $43.6(10.3)$ & $49.6(8.8)$ & \\
\hline sex: male & $432(43.8)$ & $221(43.4)$ & $138(44.8)$ & $73(42.9)$ & 0.902 \\
\hline educational level & & & & & 0.927 \\
\hline tertiary or below & $149(15.1)$ & $76(14.9)$ & $48(15.6)$ & $25(14.7)$ & \\
\hline university & $647(65.6)$ & $338(66.4)$ & $201(65.3)$ & $108(63.5)$ & \\
\hline postgraduate & $191(19.4)$ & $95(18.7)$ & $59(19.2)$ & $37(21.8)$ & \\
\hline marriage & & & & & 0.193 \\
\hline married & $644(65.2)$ & $328(64.4)$ & $195(63.3)$ & $121(71.2)$ & \\
\hline others & $343(34.8)$ & $181(35.6)$ & $113(36.7)$ & $49(28.8)$ & \\
\hline income & & & & & 0.026 \\
\hline $\mathrm{NTD}<15000$ & $168(17.0)$ & $90(17.7)$ & $50(16.2)$ & $28(16.5)$ & \\
\hline NTD 15001-30000 & $130(13.2)$ & $70(13.8)$ & $37(12.0)$ & $23(13.5)$ & \\
\hline NTD 30001-50000 & $346(35.1)$ & $180(35.4)$ & $120(39.0)$ & $46(27.1)$ & \\
\hline NTD 50001-70000 & $176(17.8)$ & $74(14.6)$ & $57(18.5)$ & $45(26.5)$ & \\
\hline $\mathrm{NTD}>70000$ & $167(16.9)$ & $95(18.7)$ & $44(14.3)$ & $28(16.5)$ & \\
\hline area & & & & & $<0.001$ \\
\hline urban & $649(65.8)$ & $337(66.2)$ & $179(58.1)$ & $133(78.2)$ & \\
\hline suburban/rural & $338(34.2)$ & $172(33.8)$ & $129(41.9)$ & $37(21.8)$ & \\
\hline residency & & & & & 0.059 \\
\hline northern & $662(67.1)$ & $335(65.8)$ & $199(64.6)$ & $128(75.3)$ & \\
\hline middle & $115(11.7)$ & $59(11.6)$ & $40(13.0)$ & $16 \quad(9.4)$ & \\
\hline southern & $163(16.5)$ & $96(18.9)$ & $48(15.6)$ & $19(11.2)$ & \\
\hline east/archipelagos & $47 \quad(4.8)$ & $19 \quad(3.7)$ & $21 \quad(6.8)$ & $7 \quad(4.1)$ & \\
\hline $\begin{array}{l}\text { have a regular family } \\
\text { physician }\end{array}$ & $508(51.5)$ & $315(61.9)$ & $123(39.9)$ & $70(41.2)$ & $<0.001$ \\
\hline $\begin{array}{l}\text { satisfied with the } \\
\text { experience of the }\end{array}$ & $667(67.6)$ & $383(75.2)$ & $194(63.0)$ & $90(52.9)$ & $<0.001$ \\
\hline
\end{tabular}


primary clinic

2

3

Peer] reviewing PDF | (2020:04:47877:2:0:NEW 4 Aug 2020) 


\section{Table 2 (on next page)}

Table 2. Association between the average rating of respondents to each factor when selecting an outpatient facility and their preferred outpatient institution 
1 Table 2. Association between the average rating of respondents to each factor when selecting an 2 outpatient facility and their preferred outpatient institution

\begin{tabular}{|c|c|c|c|c|c|}
\hline \multirow{4}{*}{$\begin{array}{l}\text { factors considered when } \\
\text { selecting an outpatient facility }\end{array}$} & \multicolumn{4}{|c|}{ preferred institution for outpatient visit } & \multirow{4}{*}{$p$ value } \\
\hline & Total & $\begin{array}{l}\text { primary } \\
\text { clinic }\end{array}$ & $\begin{array}{l}\text { general } \\
\text { hospital }\end{array}$ & $\begin{array}{c}\text { medical } \\
\text { center }\end{array}$ & \\
\hline & $n=987$ & $\mathrm{n}=509$ & $\mathrm{n}=308$ & $\mathrm{n}=170$ & \\
\hline & \multicolumn{4}{|c|}{ average rating of respondents } & \\
\hline physicians are highly reputable & $4.65 \pm 0.71$ & $4.66 \pm 0.69$ & $4.55 \pm 0.78$ & $4.81 \pm 0.58$ & $0.001 * * *$ \\
\hline physicians explained in detail & $4.57 \pm 0.75$ & $4.58 \pm 0.74$ & $4.49 \pm 0.80$ & $4.68 \pm 0.69$ & $0.027^{*}$ \\
\hline $\begin{array}{l}\text { physicians have a good medical } \\
\text { practice }\end{array}$ & $4.47 \pm 0.80$ & $4.40 \pm 0.82$ & $4.46 \pm 0.77$ & $4.66 \pm 0.72$ & $0.001^{* * *}$ \\
\hline $\begin{array}{l}\text { consider the severity of the } \\
\text { disease }\end{array}$ & $4.37 \pm 0.91$ & $4.34 \pm 0.94$ & $4.36 \pm 0.85$ & $4.48 \pm 0.94$ & 0.235 \\
\hline $\begin{array}{l}\text { the institution has advanced } \\
\text { equipment }\end{array}$ & $4.35 \pm 0.86$ & $4.25 \pm 0.86$ & $4.34 \pm 0.85$ & $4.65 \pm 0.79$ & $<0.001^{* * *}$ \\
\hline $\begin{array}{l}\text { the institution has high-quality } \\
\text { drugs }\end{array}$ & $4.34 \pm 0.92$ & $4.28 \pm 0.93$ & $4.28 \pm 0.95$ & $4.62 \pm 0.75$ & $<0.001 * * *$ \\
\hline physicians are not in a hurry & $4.30 \pm 0.87$ & $4.32 \pm 0.88$ & $4.22 \pm 0.89$ & $4.40 \pm 0.81$ & 0.071 \\
\hline physicians are gracious and kind & $4.25 \pm 0.85$ & $4.25 \pm 0.85$ & $4.22 \pm 0.85$ & $4.30 \pm 0.86$ & 0.645 \\
\hline have good medical experience & $4.24 \pm 0.79$ & $4.25 \pm 0.79$ & $4.20 \pm 0.79$ & $4.29 \pm 0.80$ & 0.414 \\
\hline the institution has friendly staff & $4.15 \pm 0.96$ & $4.12 \pm 1.00$ & $4.14 \pm 0.91$ & $4.22 \pm 0.94$ & 0.500 \\
\hline $\begin{array}{l}\text { the institution has convenient } \\
\text { transportation }\end{array}$ & $4.13 \pm 0.96$ & $4.11 \pm 0.95$ & $4.13 \pm 0.94$ & $4.18 \pm 1.03$ & 0.722 \\
\hline $\begin{array}{l}\text { the institution has diverse } \\
\text { specialties }\end{array}$ & $4.09 \pm 0.99$ & $3.97 \pm 1.06$ & $4.12 \pm 0.90$ & $4.39 \pm 0.87$ & $<0.001 * * *$ \\
\hline waiting time is not too long & $3.90 \pm 0.93$ & $3.91 \pm 0.93$ & $3.94 \pm 0.86$ & $3.78 \pm 1.02$ & 0.171 \\
\hline $\begin{array}{l}\text { the institution was recommended } \\
\text { by friends or relatives }\end{array}$ & $3.55 \pm 0.99$ & $3.54 \pm 1.01$ & $3.50 \pm 0.89$ & $3.71 \pm 1.05$ & 0.074 \\
\hline $\begin{array}{l}\text { institutions with a good } \\
\text { reputation }\end{array}$ & $3.53 \pm 1.03$ & $3.46 \pm 1.03$ & $3.45 \pm 0.99$ & $3.88 \pm 1.05$ & $<0.001 * * *$ \\
\hline $\begin{array}{l}\text { the visibility of medical } \\
\text { institutions is high }\end{array}$ & $3.43 \pm 1.06$ & $3.39 \pm 1.07$ & $3.41 \pm 0.97$ & $3.62 \pm 1.18$ & $0.042^{*}$ \\
\hline $\begin{array}{l}\text { willing to prescribe for chronic } \\
\text { diseases }\end{array}$ & $3.40 \pm 1.16$ & $3.36 \pm 1.16$ & $3.40 \pm 1.16$ & $3.50 \pm 1.16$ & 0.381 \\
\hline physicians are famous & $3.32 \pm 0.98$ & $3.25 \pm 0.97$ & $3.31 \pm 0.94$ & $3.52 \pm 1.03$ & $0.007^{* *}$ \\
\hline $\begin{array}{l}\text { physicians with a good } \\
\text { reputation }\end{array}$ & $3.29 \pm 0.91$ & $3.23 \pm 0.90$ & $3.26 \pm 0.91$ & $3.50 \pm 0.89$ & $0.003^{* *}$ \\
\hline low copayment & $3.08 \pm 1.16$ & $3.07 \pm 1.14$ & $3.15 \pm 1.17$ & $3.00 \pm 1.19$ & 0.394 \\
\hline
\end{tabular}

$3 \quad * * * \mathrm{p} \leq 0.001, \quad * * \mathrm{p} \leq 0.01, \quad * \mathrm{p} \leq 0.05$ 


\section{Table 3 (on next page)}

Table 3. Exploratory factor analysis loads and variance percentages for factors considered when selecting an outpatient facility 
1 Table 3. Exploratory factor analysis loads and variance percentages for factors considered when 2 selecting an outpatient facility

\begin{tabular}{|c|c|c|c|}
\hline \multirow[b]{2}{*}{ factor items } & \multicolumn{3}{|c|}{ factors loads } \\
\hline & $\begin{array}{l}\text { factor I: } \\
\text { physician } \\
\text { factor }\end{array}$ & $\begin{array}{l}\text { factor II: } \\
\text { image \& } \\
\text { reputation }\end{array}$ & $\begin{array}{l}\text { factor III: } \\
\text { facility \& } \\
\text { medication }\end{array}$ \\
\hline physicians explained in detail & 0.922 & & \\
\hline physicians are highly reputable & 0.855 & & \\
\hline physicians are not in a hurry & 0.851 & & \\
\hline physicians are gracious and kind & 0.780 & & \\
\hline $\begin{array}{l}\text { the ability of the physician is well } \\
\text { known }\end{array}$ & 0.488 & & \\
\hline physicians with a good reputation & & 0.851 & \\
\hline physicians are famous & & 0.747 & \\
\hline institutions with a good reputation & & 0.656 & \\
\hline the visibility of medical institutions & & 0.545 & \\
\hline the institution has advanced equipment & & & -0.817 \\
\hline drug quality is trustworthy & & & -0.781 \\
\hline diverse specialty & & & -0.741 \\
\hline sum of squared loading (eigenvalue) & 5.239 & 1.515 & 0.653 \\
\hline percentage of variance explained $(\%)$ & 43.659 & 12.627 & 5.438 \\
\hline $\begin{array}{c}\text { cumulative percentage of variance } \\
\text { explained }(\%)\end{array}$ & 43.659 & 56.286 & 61.724 \\
\hline Cronbach's alpha & 0.905 & 0.840 & 0.792 \\
\hline
\end{tabular}

3 Kaiser-Meyer-Olkin (KMO): 0.868 Bartlett sphericity tests $(\mathrm{P}<0.001)$.

4 Six factors were removed because the factor load was too low $(<0.4)$ or because of cross-

5 loading. The removed factors were "consider the severity of the disease," "institution has

6 convenient transportation," "reasonable waiting time," "institution was recommended by 7 friends or relatives," "willing to prescribe for chronic diseases," and "low copayment." 


\section{Table 4 (on next page)}

Table 4. Results of the logistic regression for predicting "visit to an outpatient clinic of the medical center for an illness" 
1 Table 4. Results of the logistic regression for predicting "visit to an outpatient clinic of the medical center for an illness"

\begin{tabular}{|c|c|c|c|c|c|c|c|c|c|}
\hline \multirow{3}{*}{$\begin{array}{l}\text { variables } \\
\text { age }\end{array}$} & \multicolumn{3}{|c|}{ MODEL 1} & \multicolumn{3}{|c|}{ MODEL 2} & \multicolumn{3}{|c|}{ MODEL 3} \\
\hline & \multirow{2}{*}{$\frac{\operatorname{Exp}(\mathrm{B})}{1.031 * * *}$} & \multicolumn{2}{|c|}{$95 \%$ CI of OR } & \multirow{2}{*}{$\frac{\operatorname{Exp}(\mathrm{B})}{1.028 * * *}$} & \multicolumn{2}{|c|}{$95 \%$ CI of OR } & \multirow{2}{*}{$\frac{\operatorname{Exp}(\mathrm{B})}{1.027^{* * *}}$} & \multicolumn{2}{|c|}{$95 \% \mathrm{CI}$ of OR } \\
\hline & & 1.019 & 1.043 & & 1.016 & 1.041 & & 1.014 & 1.041 \\
\hline male & 0.821 & 0.582 & 1.159 & 0.817 & 0.575 & 1.162 & 0.786 & 0.544 & 1.134 \\
\hline past experience in primary clinics & $0.500 * * *$ & 0.429 & 0.584 & $0.509 * * *$ & 0.435 & 0.595 & $0.557 * * *$ & 0.467 & 0.663 \\
\hline have regular family physician & $0.694 *$ & 0.489 & 0.986 & $0.676^{*}$ & 0.471 & 0.969 & $0.659 *$ & 0.457 & 0.952 \\
\hline consider copayment is important & $0.643^{*}$ & 0.441 & 0.938 & $0.525 * * *$ & 0.354 & 0.781 & $0.547 * *$ & 0.365 & 0.818 \\
\hline factor I: $\quad$ physician factor & & & & $0.717 *$ & 0.523 & 0.984 & 0.896 & 0.705 & 1.137 \\
\hline factor II: image and reputation & & & & 1.257 & 0.975 & 1.621 & $1.289 *$ & 1.042 & 1.593 \\
\hline factor III: facility and medication & & & & $2.218 * * *$ & 1.514 & 3.249 & $1.802 * * *$ & 1.392 & 2.332 \\
\hline lived in an urban area & & & & & & & 1.286 & 0.844 & 1.957 \\
\hline \multicolumn{10}{|l|}{ lived area $:$ northern Taiwan } \\
\hline middle Taiwan & & & & & & & 0.763 & 0.416 & 1.398 \\
\hline southern Taiwan & & & & & & & $0.572 *$ & 0.330 & 0.989 \\
\hline eastern Taiwan & & & & & & & 1.220 & 0.484 & 3.073 \\
\hline \multicolumn{10}{|l|}{ education : high school } \\
\hline college & & & & & & & 0.742 & 0.465 & 1.184 \\
\hline postgraduate & & & & & & & 0.753 & 0.412 & 1.374 \\
\hline \multicolumn{10}{|l|}{ income $:$ NTD $\leq 30000$} \\
\hline NTD 30001-50000 & & & & & & & 0.692 & 0.433 & 1.107 \\
\hline NTD $>50000$ & & & & & & & 1.064 & 0.670 & 1.689 \\
\hline -2log likelihood & \multicolumn{3}{|c|}{854.516} & \multicolumn{3}{|c|}{812.212} & \multicolumn{3}{|c|}{798.631} \\
\hline Model $\chi^{2}$ & \multicolumn{3}{|c|}{$513.757(\mathrm{df}=5) * * *$} & \multicolumn{3}{|c|}{$556.061(\mathrm{df}=8) * * *$} & \multicolumn{3}{|c|}{$569.642(\mathrm{df}=16) * * *$} \\
\hline Step $\chi^{2}$ & \multicolumn{3}{|c|}{$513.757(\mathrm{df}=5) * * *$} & \multicolumn{3}{|c|}{$42.304(\mathrm{df}=3) * * *$} & \multicolumn{3}{|c|}{$13.581(\mathrm{df}=8) \mathrm{p}=0.093$} \\
\hline Nagelkerke R2 & \multicolumn{3}{|c|}{0.541} & \multicolumn{3}{|c|}{0.574} & \multicolumn{3}{|c|}{0.585} \\
\hline $\begin{array}{l}\text { percentage of correctly classifying } \\
\text { the outcome }\end{array}$ & \multicolumn{3}{|c|}{$82.0 \%$} & \multicolumn{3}{|c|}{$82.9 \%$} & \multicolumn{3}{|c|}{$82.7 \%$} \\
\hline
\end{tabular}

$2 * * * \mathrm{p}<0.001, \quad * * \mathrm{p}<0.01, \quad * \mathrm{p}<0.05$ 